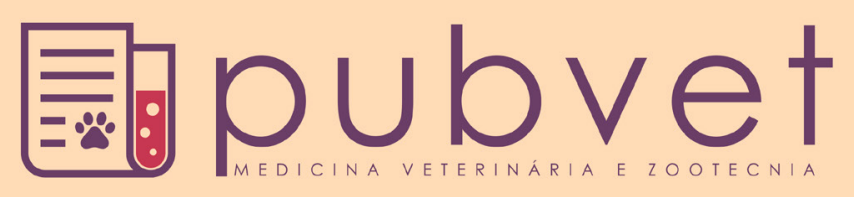

HTTP://DX.DOI.ORG/10.22256/PUBVET.V11N5.476-481

\title{
Lipidose hepática secundaria à Colangiohepatite em felino doméstico sem raça definida: Relato de caso
}

Lilian Tupinambar dos Reis Lima ${ }^{1}$, Estéfane Kelly Dias Araújo ${ }^{1}$, Mayara Galeno da Silva ${ }^{1}$, Tiago Gonçalves Azevëdo da Fonsëca Honório ${ }^{1}$, Sérgio Diego Passos Costa ${ }^{2 *}$, Karoline Figueredo Rodrigues ${ }^{2,}$ Murilo Ramos Bastos de Oliveira ${ }^{2}$

${ }^{I}$ Graduando em Medicina Veterinária, Universidade Federal do Piaui (UFPI). Teresina, Piauí, Brasil. ${ }^{2}$ Médico(a) Veterinário(a), Residente em clínica e cirurgia de cães e gatos, Universidade Federal do Piaui (UFPI). Teresina, Piauí, Brasil. *Autor para correspondência, E-mail: sergiodiegoveterinario@yahoo.com.br

RESUMO. Este relato mostra o caso de um felino sem raça definida, de um ano e quatro meses de idade diagnosticado com lipidose hepática secundaria à colangiohepatite. Relata a importância dos exames complementares no diagnóstico da doença e o tratamento à base de suporte nutricional contendo alto teor proteico, que demonstrou ser essencial na recuperação do paciente.

Palavras chaves: disfunção hepática, hiperbilirrubinemia, icterícia

\section{Hepatic lipidosis secondary to Cholangiohepatitis in domestic feline without definite breed - Case report}

\begin{abstract}
This report shows a case of feline without definite breed, whit one-year and four-month-old diagnosed with hepatic lipidosis secondary to cholangiohepatitis. It reports the importance of complementary tests in the diagnosis of the disease and the treatment based on nutritional support containing high protein content, which has been shown to be essential for patient recovery.
\end{abstract}

Keywords: Hepatic dysfunction, hyperbilirubinemia, jaundice

\section{Lipidosis hepática secundaria a colangiohepatitis en felino mestizo: Reporte de un caso}

RESUMEN. El presente caso muestra un felino mestizo, de un año y cuatro meses de edad, con diagnóstico de lipidosis hepática secundaria a colangiohepatitis. Informa sobre la importancia de las pruebas complementarias en el diagnóstico de la enfermedad y el tratamiento de la base de apoyo nutricional que contiene un alto contenido de proteínas, que resultó ser esencial en la recuperación del paciente.

Palabras clave: disfunción hepática, hiperbilirrubinemia, ictericia

\section{Introdução}

A lipidose hepática felina (LHF) é uma das doenças hepatobiliares mais comum e potencialmente fatal que acomete os gatos domésticos (Griffin, 2000). Foi descrita pela primeira vez por Barsanti et al em 1977. É caracterizada pelo acúmulo lipídico nos hepatócitos, podendo conduzir à disfunção hepática grave ou morte (Dimski, 1997, Center, 2005). O acúmulo de lipídeos nos hepatócitos torna-se exagerado, de modo que o fígado não é capaz de metaboliza-los e removê-los de suas células (Ferreira Neto et al., 1977). 
Os gatos apresentam predisposição a acumular triacilgliceróis nos seus hepatócitos através da vacuolização graxa, que quando severa, reflete uma alteração patológica metabólica subjacente. Esta acumulação deve-se ao fato da taxa de síntese hepática de triacilgliceróis superar a taxa de dispersão dos mesmos. Os triacilgliceróis hepáticos são produzidos a partir dos ácidos graxos originários dos lipídios contidos na dieta, nas reservas adiposas, ou da síntese hepática de novo. No caso da LHF, grande parte dos gatos que a desenvolvem são obesos e, ao sofrerem um processo patológico causador de anorexia, mobilizam ácidos graxos das reservas adiposas através de lipólise (Ettinger and Feldman, 2004). Com efeito, o substrato energético utilizado deixa de ser a glucose e passa a ser os ácidos graxos e as cetonas (Szabo et al., 2000). A excessiva acumulação de triacilgliceróis nos hepatócitos afeta a função hepática e pode culminar em morte (Hall et al., 1997).

A LHF pode ser primária (lipidose hepática felina idiopática), desenvolvendo-se devido à ingestão inadequada de alimento durante períodos de perda forçada de peso, privação de alimento não intencional, mudança de alimentação, alterações ambientais ou stress (Blanchard et al., 2002). Embora gatos de qualquer idade, raça e sexo possam ser acometidos, nota-se uma maior incidência em fêmeas, animais previamente obesos e gatos de meia-idade (Watson and Bunch, 2010). Sherding (1994) recomenda que gatos obesos emagreçam na taxa de $0,5 \%$ por semana, de forma a evitar a ocorrência de lipidose.

A LHF secundária tem patogênese semelhante à primaria, porem exacerbada por uma resposta neuroendócrina mais acentuada ao estresse. Ela pode acometer gatos menos obesos em relação à lipidose primária, ou até mesmo gatos de bom escore corporal ou abaixo do ideal (Watson and Bunch, 2010). Stonehewer (2004) afirma que a lipidose secundaria, é assim denominada, quando ocorre como consequência de qualquer enfermidade que cause anorexia em gatos, sendo mais frequente em animais que apresentam pancreatite, diabetes melito, colangites, colangiohepatite, outros distúrbios hepáticos, doenças intestinais ou neoplasias, onde sua sintomatologia clinica pode ser complicada pela doença concomitante.

Os gatos afetados por lipidose hepática desenvolvem um quadro clínico com anorexia, perda de peso, atrofia muscular, icterícia, desidratação, diarreia, salivação, depressão e, em casos mais graves, sintomatologia neurológica associada à encefalopatia hepática. $\mathrm{O}$ diagnóstico é baseado em dados obtidos no histórico, exame físico, exames complementares e principalmente nos achados citológicos e/ou histopatológicos de biópsia hepática ou necropsia, sendo que o diagnóstico definitivo é obtido somente por meio da análise histopatológica (Griffin, 2000).

O hemograma completo pode revelar leve anemia não regenerativa normocítica e normocrômica. O leucograma pode se apresentar inalterado. No entanto, é possível a ocorrência de leucocitose de estresse ou neutrofílica, em razão da presença de focos inflamatórios (Dimski, 1997, Center, 2005). Uma suave neutropenia também pode estar presente. As anormalidades mais consistentes são encontradas no perfil bioquímico. O nível sérico das enzimas alanina amino transferase (ALT) e aspartato amino transferase (AST) está quase sempre aumentado, mas não na magnitude do aumento da fosfatase alcalina (FA) que geralmente apresenta aumento evidente (Blanchard et al., 2002). A atividade da enzima gama glutamil transferase (GGT) pode apresentarse normal ou apenas levemente aumentada, sendo um indicador mais sensível de processos colestáticos (Webster and Cooper, 2009).

Hiperbilirrubinemia e incremento de ácidos biliares séricos são comuns. Concentração aumentada de colesterol e creatinina, diminuição da uréia nitrogenada no sangue, hipocalemia, hiperglicemia e leve diminuição de albumina são achados ocasionais (Ferreira; Mello, 2003). Achados ultrassonográficos comuns incluem hepatomegalia e aumento da ecogenicidade homogênea e difusa do fígado (Sherding, 1994).

Segundo Nelson and Couto (2015) o aspecto mais importante do tratamento é o suporte nutricional completo juntamente com o tratamento da doença concomitante e possivelmente desencadeante. $\mathrm{O}$ tratamento consiste em estabilizar o quadro clinico do animal, realizando um suporte nutricional e corrigindo a desidratação e o desequilíbrio de eletrólitos (Center, 2005). Reside num correto suporte nutricional, que satisfaça as necessidades proteicas e calóricas do paciente, revertendo os sinais clínicos apresentados (Blanchard et al., 2002).

$\mathrm{O}$ manejo terapêutico deve ser feito primariamente através da alimentação intensa, com uma dieta de alto teor proteico (Watson and Bunch, 2010). Além de alto teor de proteína, é 
interessante que a dieta utilizada apresente todos os nutrientes essenciais para o gato, incluindo arginina, taurina, vitamina $\mathrm{A}$, niacina e ácido araquidônico, distribuindo a dieta em pequenas quantidades, sendo esta a melhor maneira de garantir uma boa digestão e absorção dos nutrientes e das calorias (Ferreira Neto et al., 1977).

A reposição de fluidos deve impor-se como o primeiro passo do tratamento do paciente LHF, sendo feita a administração por via endovenosa, com fluidos cristaloides que não contenham lactato ou glicose na sua composição (Center, 2005, Ettinger and Feldman, 2004), pois o metabolismo hepático do lactato é afetado durante a lipidose (Birchard and Sherding, 2008).

A alimentação enteral deve ser iniciada o quanto antes no curso da doença e deve ser mantida até que o animal volte a se alimentar voluntariamente. Os métodos mais utilizados para a alimentação enteral são via nasoesofágica, esofagostomia ou por colocação de tubo gástrico (Griffin, 2000). Na maioria dos casos, o método de eleição, é a alimentação por sonda nasogástrica, pois é bastante eficaz numa primeira abordagem ao paciente, não requer anestesia ou sedação, nem necessita de qualquer procedimento cirúrgico (Reilly, 2006).

No momento em que o animal inicia a alimentação voluntária após a colocação da sonda alimentar, esta deve permanecer no local por no mínimo 5 dias antes de ser removida para assegurar à cicatrização adequada entre estômago e a parede corpórea e evitar contaminação peritoneal (Nelson and Couto, 2015). Drogas antieméticas podem ser utilizadas em caso de vômitos, desde que não haja obstrução gastrintestinal (Ferreira Neto et al., 1977). Recidivas são raras, e quanto mais cedo o inicio do tratamento melhor é o prognostico (Birchard and Sherding, 2008).

\section{Relato de caso}

Foi atendido no Hospital Veterinário Universitário, "Médico Veterinário Jeremias Pereira da Silva" da Universidade Federal do Piauí (HVU - UFPI), Teresina, Piauí (PI), no dia 26 de Setembro de 2016, um felino macho, sem raça definida (SRD), de um ano e quatro meses de idade, com $3,5 \mathrm{~kg}$, apresentando um quadro de hiporexia há três dias, adipsia, apatia e êmese. O tutor afirmou que o animal tinha acesso à rua constantemente, mas, após os sinais e sintomas apresentados se isolou completamente, não apresentou diarreia, vacinação apenas a antirrábica, vermifugação desatualizada. Ao exame físico foram constatadas mucosas normocoradas (Figura 1) e o abdômen sem edema aparente.

Foram solicitados alguns exames laboratoriais como hemograma, bioquímica sérica [Glicose; Ureia; Creatinina; Alanina aminotransferase ALT; Aspartato aminotransferase - AST; Fosfatase Alcalina; Gama-glutamil transferase GGT; Amilase; Proteína total; Albumina, Globulina; Bilirrubina (total, conjugada, nãoconjugada) e Triglicerídeos], além de ultrassonografia abdominal.

Diante do quadro clinico do paciente, devido à hiporexia e à adipsia e com o consentimento do tutor, o animal foi submetido à internação, para avaliação, administração de fluidoteparia intravenosa visando repor as necessidades hidroeletrolíticas e medicamentos que vizassem reverter o quadro clinico apresentado.

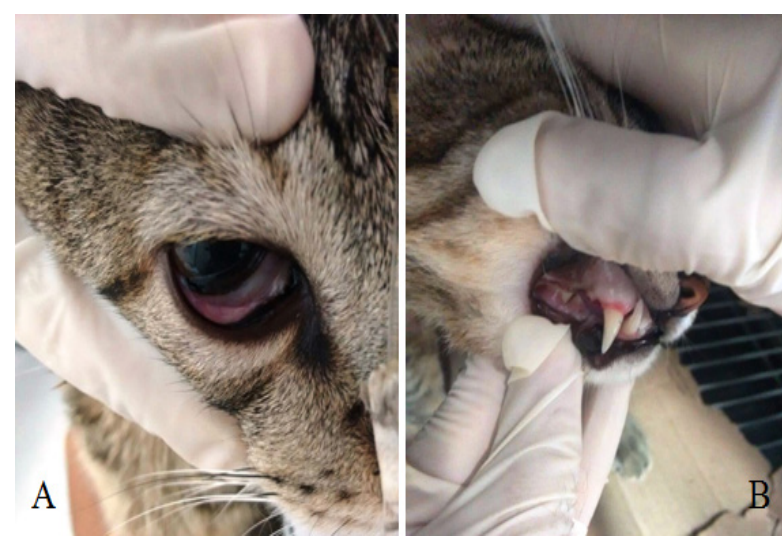

Figura 1. A - Mucosa ocular normocorada. B - mucosa oral normocorada. Fonte: Arquivo Pessoal

Mediante aos resultados dos exames solicitados, durante o periodo de internação, iniciou-se o tratamento com o auxilio de sonda nasogástrica (figura 2), com Nutralife (2 gramas, SID), Promum Cat Pasta (4 gramas, SID), Glicopan Suspensão (1,8ml, BID), Legalon $64 \mathrm{mg} / 5 \mathrm{ml}(5,5 \mathrm{ml}, \mathrm{SID})$ e Patê a/d diluido em aguá e administrado com o auxílio de seringa. Durante os dias que ficou internado, o paciente foi apresentando melhora do quadro clinico, no terceiro dia observou-se que ele já se alimentava e bebia sozinho, sem o auxilio da sonda nasogástrica. 


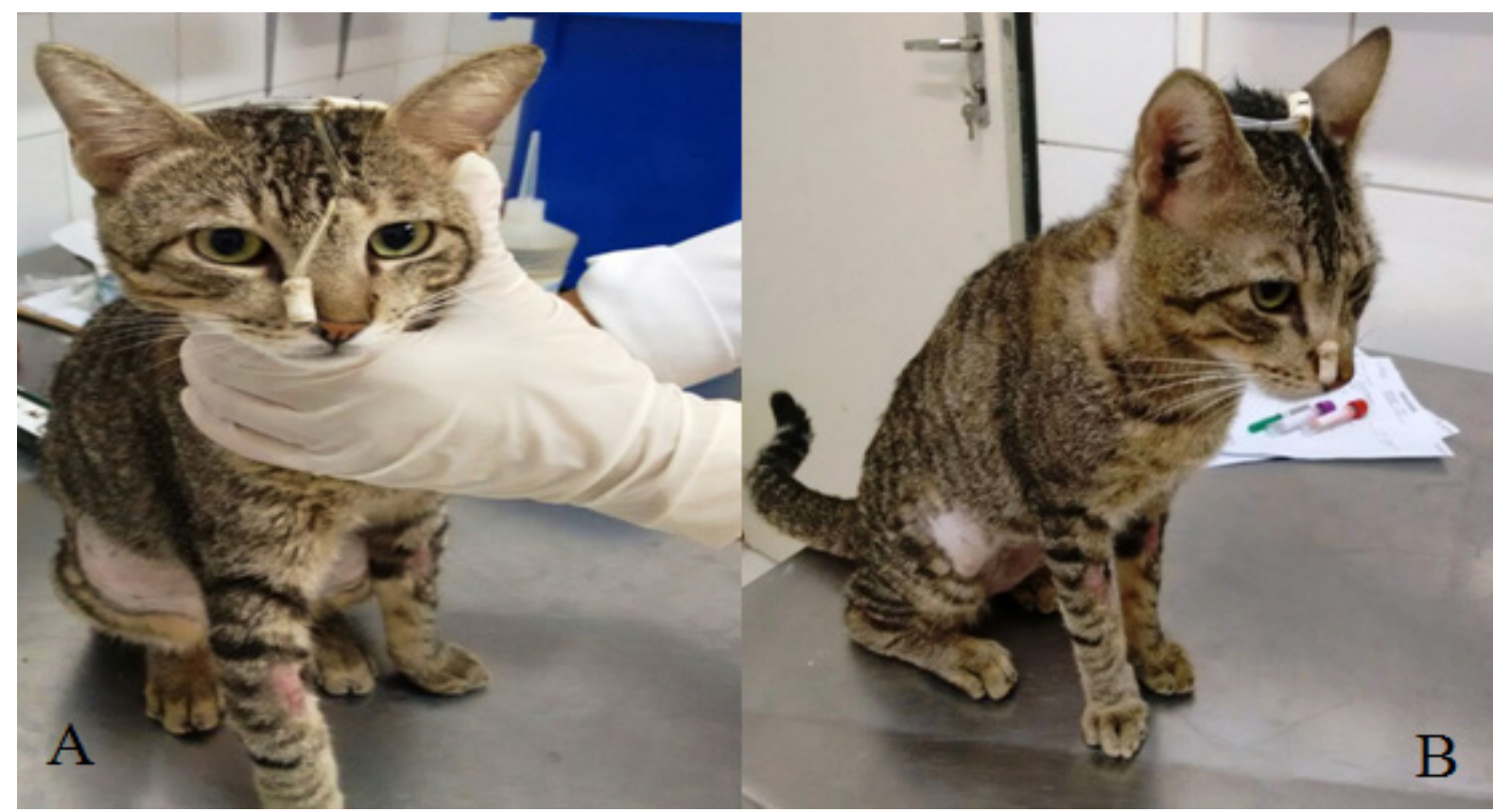

Figura 2. A e B - Sonda nasogástrica posicionada em felino. Fonte: Arquivo Pessoal.

Após avaliação médica e recuperação apresentada pelo paciente, o mesmo recebeu alta no dia 1 de Outubro de 2016. O tratamento foi mantido com Promun Cat (4 gramas, SID, durante 10 dias), Glicopan Pet (1,8ml, BID, durante 30 dias), Legalon $64 \mathrm{mg} / 5 \mathrm{ml}$ (5,5ml, SID, durante 30 dias).

\section{Resultados e Discussão}

Suspeita-se de lipidose hepática com base no histórico, exame físico, exames complementares e principalmente nos achados citológicos e/ou histopatológicos de biópsia hepática ou necropsia, sendo que o diagnóstico definitivo é obtido somente por meio da análise histopatológica (Griffin, 2000). Neste relato de caso o diagnóstico se deu com base principalmente no hemograma, bioquímica sérica e principalmente através do laudo ultrassonográfico, não foi realizada biópsia hepática e nem análise histopatológica.

O animal apresentou hiporexia, episódios eméticos, apatia, que de acordo com a literatura são alguns dos sinais e sintomas apresentados por pacientes acometidos com a hepatopatia, não apresentando icterícia, diarreia e salivação. O paciente não apresentou ao exame físico nenhuma característica especifica da doença, o que demonstrou a importância dos exames complementares para confirmação da suspeita.

Dimski (1997) afirma que os exames laboratoriais revelam leve anemia não regenerativa normocítica e normocrômica e o leucograma pode se apresentar inalterado. O nível sérico das enzimas alanina amino transferase (ALT) e aspartato amino transferase (AST) está quase sempre aumentado, mas não na magnitude do aumento da fosfatase alcalina (FA) que geralmente apresenta aumento evidente. A atividade da enzima gama glutamil transferase (GGT) pode apresentar-se normal ou apenas levemente aumentada, sendo um indicador mais sensível de processos colestáticos, hiperbilirrubinemia e incremento de ácidos biliares séricos são comuns.

Ao hemograma foi observada leucocitose com desvio à esquerda e alta atividade de neutrófilos segmentados e bastonetes, nos exames bioquímicos a enzima hepática Alanina aminotransferase (ALT) se apresentou aumentada intensamente, Aspartato aminotransferase (AST) elevada e houve hiperbilirrubinemia, sendo estas, de acordo com a literatura, características laboratoriais de Colangiohepatite Felina. O laudo de ultrassonografia revelou parênquima hepático difusamente hiperecóico, com ecogenicidade e ecotextura aumentados e margens da veia porta proeminentes (Figura 3). Este quadro trata-se de Lipidose hepática Felina; onde Sherding (1994) já havia afirmado que os achados ultrassonográficos comuns para LHF incluem hepatomegalia e aumento da ecogenicidade homogênea e difusa do fígado. Constatou-se tratar de um quadro de Lipidose Hepática Felina secundária, tendo como doença concomitante Colangiohepatite.

A LHF secundária é assim denominada quando ocorre como consequência de qualquer 
enfermidade que cause anorexia ou hiporexia em gatos e sua sintomatologia pode ser complicada pela doença concomitante (Stonehewer, 2004). Nelson and Couto (2015) acreditam que felinos costumam ser acometidos por Colangites e inflamações no trato biliar devido a uma particularidade anatômica que possuem, o ducto pancreático se une ao ducto biliar comum antes de se abrir para o duodeno. Sendo assim, existe maior possibilidade de ascensão bacteriana do intestino além do ducto biliar estar mais suscetível a alterações decorrentes de inflamações pancreáticas.

A Colangiohepatite levou o paciente relatado a um quadro de hiporexia, desta forma os níveis de glicose sanguínea decresceram e diminuíram a secreção de insulina, ocorrendo um aumento no nível de glucagon, que por sua vez fez lipólise periférica, liberando ácidos graxos na circulação sendo convertidos em triglicerídeos, que se acumularam nos hepatócitos, evoluindo para uma lipidose, além de que gatos são animais que aparentam estarem em continua gliconeogênese (Center, 2005). Divergente à literatura, a bioquímica sérica revelou níveis normais para Triglicérides e Gama-glutamil transferase (GGT) e níveis baixos para Fosfatase Alcalina.

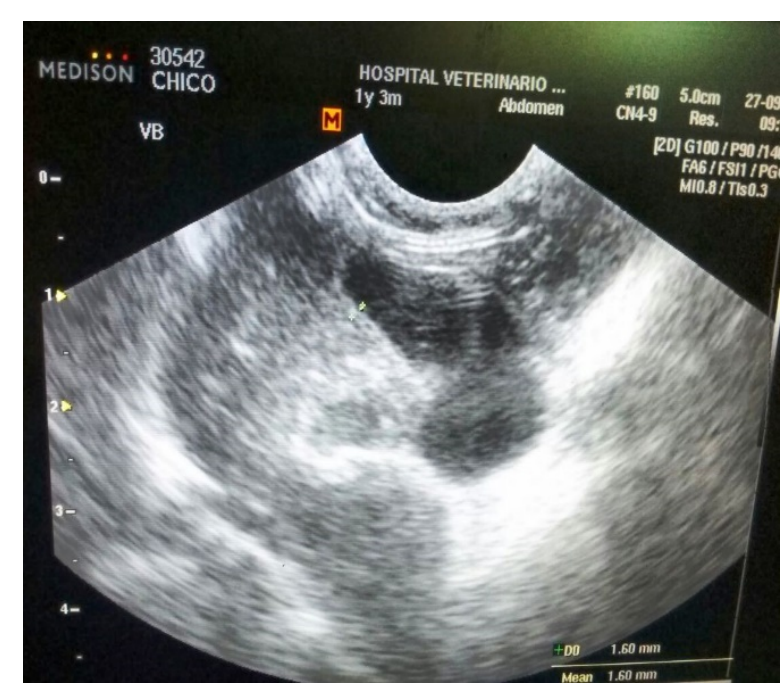

Figura 3: Parênquima hepático difusamente hiperecóico. Ecogenicidade e ecotextura aumentadas, sugestivo de Lipidose hepática. Fonte: Arquivo Pessoal

\section{Conclusão}

A lipidose hepática e a colangiohepatite são as principais hepatopatias dos felinos domésticos, sendo que em casos de LHF secundaria, a colangiohepatite pode estar associada como doença base, como foi descrito no caso então relatado.
Neste relato de caso os exames laboratoriais e a ultrassonografia abdominal, foram muito importantes para se chegar ao diagnostico, já que ao exame físico o animal não apresentou características específicas de hepatopatia, como por exemplo, mucosas ictéricas.

Outro aspecto importante foi o tratamento, inicialmente com fluidoterapia por via intravenosa repondo as suas necessidades hidroeletroliticas e o suporte nutricional com alto teor proteico, com uma dieta apresentando todos os nutrientes essenciais para o gato, como arginina, taurina, vitamina A, niacina e ácido aracdônico; desta forma, mantendo um balanço energético positivo e promovendo a regeneração hepática, que foi de grande importância para a recuperação do animal e para o seu equilíbrio metabólico, revertendo os sinais clínicos apresentados.

\section{Referências Bibliográficas}

Birchard, S. J. \& Sherding, R. G. 2008. Manual Saunders: clínica de pequenos animais, São Paulo.

Blanchard, G., Paragon, B. M., Milliat, F. \& Lutton, C. 2002. Dietary L-carnitine supplementation in obese cats alters carnitine metabolism and decreases ketosis during fasting and induced hepatic lipidosis. The Journal of Nutrition, 132, 204-210.

Center, S. A. 2005. Feline hepatic lipidosis. Veterinary Clinics of North America: Small Animal Practice, 35, 225-269.

Dimski, D. S. 1997. Feline hepatic lipidosis. Seminars in veterinary medicine and surgery (small animal).

Ettinger, S. \& Feldman, E. 2004. Tratado de medicina interna veterinária: doenças do cão e do gato. Guanabara Koogan, Rio de Janeiro.

Ferreira Neto, J. M., Viana, J. M. M. E. S. \& Magalhães, L. M. 1977. Patologia clínica veterinária. Rabelo e Brasil.

Griffin, B. 2000. Feline hepatic lipidosis: treatment recommendations. Compendium on Continuing Education for the Practicing Veterinarian, 22, 910-921.

Hall, J. A., Barstad, L. A. \& Connor, W. E. 1997. Lipid composition of hepatic and adipose tissues from normal cats and from cats with idiopathic hepatic lipidosis. Journal of Veterinary Internal Medicine, 11, 238-242. 
Nelson, R. W. \& Couto, C. G. 2015. Medicina interna de pequenos animais. Elsevier Editora, Amsterdan.

Reilly, C. 2006. BSAVA Manual of canine and feline gastroenterology. Journal of Small Animal Practice, 47, 228-228.

Sherding, R. G. 1994. The cat: diseases and clinical management.

Stonehewer, J. 2004. The liver and pancreas. In: Chandler, E. A., Gaskell, R. M. \& Gaskell, C. J. (eds.) Feline medicine and therapeutics. John Wiley \& Sons, USA.

Szabo, J., Ibrahim, W. H., Sunvold, G. D., Dickey, K. M., Rodgers, J. B., Toth, I. E., Boissonneault, G. A. \& Bruckner, G. G. 2000. Influence of dietary protein and lipid on weight loss in obese ovariohysterectomized cats. American Journal of Veterinary Research, 61, 559-565.
Watson, P. J. \& Bunch, S. E. 2010. Doenças hepatobiliares no cão. In: Nelson, R. W. \& Couto, C. G. (eds.) Medicina Interna de Pequenos Animais. Elsevier, Rio de Janeiro.

Webster, C. R. L. \& Cooper, J. C. 2009. Diagnostic approach to hepatobiliary disease. In: Bonagura, J. \& Tweldt, D. (eds.) Kirk's current veterinary therapy XIV. Saunders Elsevier, USA.

\section{Article History:}

Received 18 January 2017

Accepted 4 February 2017

Available on line 29 March 2017

License information: This is an open-access article distributed under the terms of the Creative Commons Attribution License 4.0, which permits unrestricted use, distribution, and reproduction in any medium, provided the original work is properly cited. 